\title{
Production of Dextran from Leuconostoc mesenteroid
}

\author{
Anmol N. Shrivastav and Harsha Y. Vaghasiya* \\ ASPEE Shakilam Biotechnology Institute, Navsari Agricultural University, \\ Surat, Gujarat, India \\ *Corresponding author
}

Dextran can be produce by a wide range of gram positive and gram

\section{Keywords}

Dextran,

Leuconostoc mesenteroid, Beet juice, Sucrose medium

Article Info

Accepted:

15 March 2020

Available Online:

10 April 2020 negative bacteria e.g. Leuconostoc mesenteriods and Streptococcus mutant. In the present study dextran was produced from Leuconostoc mesenteriods. L. mesenteriods was isolated from idli batter identified by different biochemical parameters. Sucrose media was used for dextran production. Dextran was also produced using beet juice and compared with sucrose media. Optimum dextran production was considered according to the optimum $\mathrm{pH}$, temperature and substrate concentration. The optimum $\mathrm{pH}$ ranged between 6.5 and 7.0. Maximum dextran yield was obtained when $10 \%$ sucrose concentration was used. Optimum temperature was observed $26^{\circ} \mathrm{C}$. Production of dextran was more in natural medium (beet juice) than synthetic medium (Sucrose broth). Thus, dextran production on the laboratory scale has successfully done.

\section{Introduction}

Dextran is a group of high molecular mass of polysaccharide of D-glucose polymer in which the glucose units are joined chiefly through $\alpha-1,6$ glycosidic linkages, other through $\alpha-1,4$ or $\alpha-1,3$ glycosidic linkage $s$ and its ratio varies depending on the strain.

Dextran is a bacterial polysaccharide, which is commercially available, and it is used as drugs, especially as blood plasma volume expander. Dextran has found industrial applications in food, pharmaceutical and chemical industries as adjuvant, emulsifier, carrier and stabilizer (Bhavani and Nisha, 2010). Cross-linked dextran is known as Sephadex, which is widely used for the separation and purification of protein (Pirouzmand et al., 2017). In food industry dextran is currently used as thickener for jam and ice cream. It prevents crystallization of sugar, improves moisture retention, and maintains flavour and appearance of various food items (Ahmad et al., 2015). 
Leuconostoc mesenteroides, a heterofermentative lactic acid bacterium is particularly well adapted to sugary niches and consequently possesses a wide spectrum of biocatalytic properties useful in carbohydrate modifications.

Leuconostoc mesenteroides and its enzymes can be used to produce carbohydrates and derivatives as diverse as dextran (biopolymer), fructose, mannitol (polyol), leucrose (noncariogenic disaccharide), glucose-1-phosphate, and many others (Kim and Robyt, 1998).

In the present study, dextran was isolated by using Leuconostoc mesenteroides strain. Natural (beet juice) and synthetic media was used for the production of dextran. Dextran yield was compared from both medium.

\section{Materials and Methods}

\section{Isolation of Leuconostoc mesenteriods}

Bacterial culture was isolated from idli batter using enrichment media technique (Mukherjee et al., 1965). Sample was inoculated in a broth medium containing sucrose, tryptone, yeast extract and $\mathrm{K}_{2} \mathrm{HPO}_{4}$. $\mathrm{pH}$ was adjusted at 7.0 and autoclaved. Sodium azide $(0.005 \%)$ was added aseptically to the medium for selective isolation of dextran producing Leuconostocs species.

Inoculated broth was incubated for $24 \mathrm{~h}$ at $25^{\circ} \mathrm{C}$. After the incubation, the microorganism in this medium was plate cultured on MRS agar, which contained tween 80 for increased growth of Leuconostoc by providing oleic acid. The plates were incubated at $37{ }^{\circ} \mathrm{C}$ for 24-28 h. After that the microorganism were transferred to Macconkey agar for the cultural characterization of the Leuconostoc mesenteriods.

\section{Leuconostoc mesenteriods isolates and its} inoculums

Defined medium was used for growth of Leuconostoc mesenteriods isolated and inoculum was prepared. $10 \mathrm{ml}$ of sterile sucrose broth was inoculated by loopful of growing culture of L. mesenteriods. Culture tube was incubated at $26^{\circ} \mathrm{C}$ for $24 \mathrm{~h}$.

\section{Production of dextran}

After $24 \mathrm{~h}$ incubation, $10 \mathrm{ml}$ of inoculums was transferred into $90 \mathrm{ml}$ of sterile broth in aseptic condition. Then, again incubated at $26^{\circ} \mathrm{C}$ for $24-30 \mathrm{~h}$ for dextran production. Isolated colonies of Leuconostoc mesenteriods maintained on MRS medium. Sucrose medium was used for $L$. mesenteriods for a dextran production (Subathra Devi et al., 2014). It was Incubated at $25-30^{\circ} \mathrm{C}$ for $24-48 \mathrm{~h}$. After that equal volume of Chilled ethanol was added in the broth. The liquid was centrifuged at $10000 \mathrm{~g}$ for $15 \mathrm{~min}$. Precipitate was collected and purified. Dried powder was dextran. Various parameters checked during production. The $\mathrm{pH}$ of the broth was checked and noted as observation during production. The effect of different concentration of sucrose was studied in range from $5 \%$ to $20 \%$. The change is substrate concentration and production were noted as observation. Dextran production was determined at different temperature from $26^{\circ} \mathrm{C}-37^{\circ} \mathrm{C}$.

\section{Production of dextran from beet juice}

\section{Preparation of juice}

The sample of beet (red) washed with water and made a juice in juicer. The raw beet juice was mixed with calcium hydroxide for carbonation. Calcium carbonate was produced as precipitate at the bottom. Juice was filtered and liquid was used for dextran production. 


\section{Dextran production}

Loopful of Leuconostoc mesenteriods culture was inoculated in $10 \mathrm{ml}$ of beet juice. The tube was incubated at $26^{\circ} \mathrm{C}$ for $24 \mathrm{~h}$. After that equal volume of Chilled ethanol was added in the broth. The liquid was centrifuged at $10000 \mathrm{~g}$ for $15 \mathrm{~min}$. Precipitated dextran was collected and purified. Purified dextran was dried at $30^{\circ} \mathrm{C}$.

\section{Results and Discussion}

Leuconostoc mesenteriods is a well known dextran producing bacteria (Munir et al., 2019). Leuconostoc mesenteriods was isolated from idli batter, in this experiment. Medium composition is of critical importance for maximum production of dextran. In the present study, several parameters considered such as $\mathrm{pH}$, substrate utilization and temperature.

Effect of $\mathrm{pH}$ has been studied which that the $\mathrm{pH}$ increases production of dextran decreases. The optimum $\mathrm{pH}$ ranged between 6.5 - 7.0. Santos have studied the effect of $\mathrm{pH}$ on dextran sucrose activity and dextran production by $L$. mesenteriods and found that dextran production was obtained at $\mathrm{pH} 5.5$ (Santos et al., 2000). During this experiment, the $\mathrm{pH}$ increase, the production of dextran decreases.

The effect of different concentration of sucrose was studied from $5 \%$ to $20 \%$. It was also observed that dextran production was affect by the different concentration of sucrose. Maximum dextran yield was obtained when $10 \%$ sucrose concentration was used in the fermentation medium. Present study indicates, concentration of substrate (sucrose) decreases as the cell mass increases. Maximum dextarn yield was obtained when $10 \%$ sucrose concentration was used in the fermentation medium. Higher concentration of sucrose in the fermentation medium had an inhibitory effect, known as substrate inhibitory effect, which decreased dextran production

Dextran production was determined at different temperature from $26^{\circ} \mathrm{c}$ to $37^{\circ} \mathrm{c}$, and the maximum dextran production by Leuconostoc mesenteriods was achieved at $26^{\circ} \mathrm{c}$. as the temperature increased or decreased in dextran production was noticed. Production of dextran was more in natural medium (beet juice) than synthetic mediu (sucrose broth) at the same temperature and other conditions, which was used for synthetic medium.

The optimum temperature required for production ranges between $25^{\circ} \mathrm{C}$ to $30^{\circ} \mathrm{C}$, the range of temperature during my study was about $26^{\circ} \mathrm{C}$ to $37^{\circ} \mathrm{C}$ for $24 \mathrm{~h}$. When the incubation temperature was high, the temperature did not favour cell multiplication, and lead towards less enzyme and dextran production as compared to optimum temperature i.e. $26^{\circ} \mathrm{C}$.

Production of dextran was more in natural medium (Beet juice) than synthetic medium (Sucrose broth) at the same temperature and other conditions, which was used for synthetic medium.

Confirmation of dextran was done by solubility. Dextran is readily soluble in water i.e. in distilled water form a clear, stable solution. It showed that, the production of dextran on different media containing different salt composition. Dextran was also soluble in ethylene glycol. Dextran was insoluble in monohydric alcohol, for e.g. methanol, ethanol. Thus all this parameters significantly affect the production of dextran (Table 1-5). 
Table.1 Isolation and characterization of Leuconostoc mesenteriods

\begin{tabular}{|l|l|l|}
\hline Sr,no & $\begin{array}{l}\text { Cultural and biochemical } \\
\text { test }\end{array}$ & Observation \\
\hline $\mathbf{1}$ & Gram staining & $\begin{array}{l}\text {-gram positive } \\
\text {-coccobacili with rounded ends. }\end{array}$ \\
\hline $\mathbf{2}$ & Motility & -Motile \\
\hline $\mathbf{3}$ & Growth an MRS agar at $37^{\circ} \mathrm{C}$ & $\begin{array}{l}\text {-pale yellow colourer, smooth slimy entire } \\
\text { marginated convex colonies. }\end{array}$ \\
\hline $\mathbf{4}$ & On MacConkey agar & -Lactose fermenting pink coloured colonies. \\
\hline $\mathbf{5}$ & $\begin{array}{l}\text { Biochemical test:- } \\
\text { Indole } \\
\text { MR }\end{array}$ & $\begin{array}{l}\text {-ve } \\
\text { VP }\end{array}$ \\
& $\begin{array}{l}\text { Ve } \\
\text { Citrate }\end{array}$ \\
\hline $\mathbf{6}$ & $\begin{array}{l}\text { Carbohydrate fermentation } \\
\text { Glucose } \\
\text { Lactose } \\
\text { Mannitol }\end{array}$ & $\begin{array}{l}\text { (-ve } \\
\text { +ve } \\
\text { +ve }\end{array}$ \\
\hline & & -ve \\
\hline
\end{tabular}

Table.2 Effect of $\mathrm{pH}$ on dextran production

\begin{tabular}{|l|c|c|}
\hline Sr. no & pH of medium & Dextran yield in $\mathbf{~}$ \\
\hline $\mathbf{1}$ & 5.5 & 0.54 \\
\hline $\mathbf{2}$ & 7.0 & 1.22 \\
\hline $\mathbf{3}$ & 8.5 & 0.82 \\
\hline
\end{tabular}

Table.3 Effect of substrate concentration

\begin{tabular}{|l|c|c|}
\hline $\begin{array}{l}\text { Sr. } \\
\text { no }\end{array}$ & $\begin{array}{c}\text { Sucrose } \\
\text { concentration } \\
\text { in medium (\%) }\end{array}$ & Dextran yield in g \\
\hline $\mathbf{1}$ & 5 & 0.85 \\
\hline $\mathbf{2}$ & 10 & 0.96 \\
\hline $\mathbf{3}$ & 15 & 0.70 \\
\hline $\mathbf{4}$ & 20 & 0.55 \\
\hline
\end{tabular}

Table.4 Effect of temperature on dextran production

\begin{tabular}{|c|c|c|}
\hline Sr. no & $\begin{array}{c}\text { Temperature } \\
(\mathbf{C} \mathbf{C})\end{array}$ & $\begin{array}{c}\text { Dextran yield in gram } \\
(\mathbf{g})\end{array}$ \\
\hline $\mathbf{1}$ & 26 & 1.20 \\
\hline $\mathbf{2}$ & 30 & 0.92 \\
\hline $\mathbf{3}$ & 37 & 0.76 \\
\hline
\end{tabular}


Table.5 Production of dextran from beet juice:

\begin{tabular}{|l|l|c|}
\hline Sr. no & Beet juice & Dextran yield in (g) \\
\hline $\mathbf{1}$ & Pure juice & 2.94 \\
\hline $\mathbf{2}$ & Diluted form of juice & 2.20 \\
\hline
\end{tabular}

It is concluded in this experiment, substrate concentration that is sucrose indicated proper growth of organism in the fermentation medium. If the substrate concentration is maintained properly, high production of dextran can be achieved at optimum $\mathrm{pH}$ and temperature. The potency of produced dextran compared with standard dextran and its solubility in distilled water, it can be concluded that the precipitation and purification of dextran on the laboratory scale successfully done.

\section{References}

Ahmad, N. H., Mustafa, S., and Che Man, Y. B. (2015). Microbial Polysaccharides and Their Modification Approaches: A Review. International Journal of Food Properties 18(2), 332-347.

Bhavani AL, Nisha J (2010) Dextran: the polysaccharide with versatile uses. Int J Pharma Biosci 1:569-573.

Kim, D., and Robyt, J. F. (1994). Properties of Leuconostoc mesenteroides B512FMC constitutive dextransucrase. Enzyme and Microbial Technology 16(12), 1010-1015.

Mukherjee, S. K., Albury, M. N., Pederson,
C. S., Vanveen, A. G., and Steinkraus, K. H. (1965). Role of Leuconostoc mesenteroides in leavening the batter of idli, a fermented food of India. Applied microbiology 13(2), 227-231.

Munir, F., Saleem, Y., Munir, N., Iqbal, M.S., \& Sattar, S. (2019). Production and characterization of dextran from Leuconostoc mesenteroides NRRL B512 (f) Fermentation.

Pirouzmand, H., Khameneh, B., and Tafaghodi, M. (2017). Immunoadjuvant potential of cross-linked dextran microspheres mixed with chitosan nanospheres encapsulated with tetanus toxoid. Pharm Biol 55(1), 212-217.

Santos, M., Teixeira, J., and Rodrigues, A. R. (2000). Production of dextransucrase, dextran and fructose from sucrose using Leuconostoc mesenteroides NRRL B512(f). Biochemical Engineering Journal 4(3), 177-188.

Subathra Devi, C., Reddy, S., and Mohanasrinivasan, V. (2014). Fermentative production of dextran using Leuconostoc spp. isolated from fermented food products. Frontiers in Biology 9(3), 244-253.

\section{How to cite this article:}

Anmol N. Shrivastav and Harsha Y. Vaghasiya. 2020. Production of Dextran from Leuconostoc mesenteroid. Int.J.Curr.Microbiol.App.Sci. 9(04): 1855-1859. doi: https://doi.org/10.20546/ijcmas.2020.904.218 